\title{
Reconceptualizing natural capital and sustainable use of natural capital through Aldo Leopold's land ethic
}

\author{
Felix N. Fernando ${ }^{1}$
}

Received: 28 May 2021 / Accepted: 11 September 2021 / Published online: 11 October 2021

(c) The Author(s) 2021

\begin{abstract}
This article reconceptualizes natural capital. It categorizes natural capital into renewable natural capital and structural natural capital, and argues for exclusion of nonrenewable natural capital (such as coal and oil) from consideration as a natural capital. It presents 10 guiding principles for sustainable use of natural capital. Both tasks of reconceptualizing natural capital and identifying guiding principles for sustainable use of natural capital are inspired by Aldo Leopold's land ethic.
\end{abstract}

Keywords Land ethic $\cdot$ Biotic community $\cdot$ Ecosystem $\cdot$ Natural capital $\cdot$ Sustainability $\cdot$ Aldo Leopold

\section{Introduction}

Seventy years after the publication of A Sand County Almanac (Leopold 1949), Leopold remains a thought leader in the interdisciplinary field of socio-ecological systems (Meine 2020). Lin (2020, p. 1) outlines that the continuing influence of Leopold's ideas stem from Leopold's identification of "major foundational issues that remain unresolved: chiefly, our treatment of the natural world as merely a fund of resources, the relentless exploitation of which may threaten our very own existence." "Appreciation for and recognition of short- and long-term ecological processes that sustain humans at individual and collective levels could advance human wellbeing (Xiang 2019; Young 2019). According to Warren (2016, p. 349), Leopold's land ethic might help "people to broaden their ideals and bring themselves into line with nature's forces." Natural capital is a central concept in ecological economics (Norgaard 2010). Multiple factors contribute to (and accelerate) the depletion of natural capital including perceptual distortions (of the functions performed by natural capital) and dominant economic rationality (Wackemagel and Rees 1997). Therefore, the overall purpose of this article is to reconceptualize natural capital and construct a set of guiding principles for the sustainable use of natural capital.

Felix N. Fernando

wfernando1@udayton.edu

1 Hanley Sustainability Institute, University of Dayton, 300 College Park, Dayton, OH 45469, USA
Spash and Clayton (1997, p. 144) argue that "both the ecological and economic approaches require the factors to be protected be identified, and natural capital be shown as a cause of that protection." Leopold's ideas are central to constructing and understanding economic and ecological dynamics of human-nature relationships (Lin 2013). Leopold (1991a, p. 273) perceived that the "failure of the social and natural sciences to agree with each other" demonstrates the lack of a "common concept of land." Therefore, the first aim of this article is to construct a common concept of land by clearly outlining how different broad concepts in ecological economics such as natural capital could be bridged with the ecological concepts of ecosystems and Leopold's ideas of land and biotic community, which is presented in Sect. 2 .

Innovative natural capital conceptions could build a consensus among economists and ecologists and could translate sustainability into manageable practices (Fenech et al. 2003). With the continued and intensified depletion of natural capital, socio-ecological systems face irreversible thresholds (or tipping points) with potentially catastrophic implications for human civilizations (Aronson et al. 2007; Boehnert 2015). In addition, ignorance of non-market benefits provided by natural capital has resulted in unprecedented threats to ecological life support functions (Farley 2008). Human activity involving unsustainable extraction, exploitation, and depletion of natural capital (including impacts such as pollution) driven by short-term focused profit-driven logic

\footnotetext{
${ }^{1}$ For more information on the importance of Leopold's work, please refer "A Sand County Almanac at 70" published in SEPR, 2(1): (p.170).
} 
could impact the wellbeing of humans who are not directly involved in such activity (Dalziel et al. 2018). For example, clear-cutting and destruction of a forest to harvest the timber, could impact the air quality, water quality, and recreational enjoyment of nearby residents.

Harte (1995, p. 160) proposes that "embracing a more dynamic view of natural capital" would help to assimilate anthropocentric dynamics with ecological dynamics, and imply "some important observations for the practice of sustainability and ecological economics." A deeper understanding of natural capital would exemplify what gives rise to the attributes, configurations, and characteristics of natural capital that have the capacity to perform certain functions (De Groot et al. 2003; Schultz et al. 2015). However, as described in Sect. 3, weaknesses in natural capital definition and conceptualization make it difficult to bridge economic interpretations with ecological dynamics (Spash and Clayton 1997). Therefore, the second aim of this article is to reconceptualize natural capital based on the ideas of Leopold in a way that is ecologically consistent and captures the numerous ways in which natural capital contributes to human wellbeing. Integrating pertinent literature, Sect. 3 critically evaluates one of the most widely used and cited theorizations of natural capital presented in Costanza and Daly (1992). Section 5 details the reconceptualized natural capital.

The reconceptualized natural capital requires specific guiding principles for sustainable use of natural capital. Strong and weak sustainability are the main perspectives in ecological economics pertaining to use of natural capital. Based on pertinent literature, Sect. 4 outlines the limitations of sustainable use based on strong and weak sustainability. According to Flader (1974), Leopold was concerned not only with advancing ecological understanding of land but also with developing the tools, techniques, and criteria for better management of land. Therefore, guiding principles grounded in Leopold's thinking could guide sustainable use of natural capital that also enhances human wellbeing. The third aim of this article is to develop a set of guiding principles for sustainable use of natural capital based on the ideas of Leopold, which is presented in Sect. 6.

The integration of Leopold's ideas with the concepts of natural capital to reconceptualize natural capital and to develop guidelines for sustainable use of natural capital is important for three main reasons. First, the reenvisioning of natural capital based on the ideas of Leopold demonstrates a constructive and interdependent view of human-nature relationships, which would advance discourse in ecological economics. This is consistent with the arguments of Lin (2014, p. 111) that a Leopoldian view of ecological economics "in its ideal form, would not be a strict replacement of orthodox economics but would have occupied a different place in society's transformed consciousness." Leopold pragmatically called for tempering economic logic with insights of ecology as he recognized that economic thinking will determine decision-making (Lin 2020).

Secondly, "particular configuration of natural capital" is critical for sustained provision of ecosystem services that contribute to human wellbeing (Pelenc and Ballet 2015, p. 38). Such configurations include attributes such as biodiversity and presence of native species or native forms. Some natural capital literature recognizes the role of biodiversity as performing a regulatory function of natural capital (Ekins et al. 2003). Broadly cited natural capital management approaches (such as those described in Costanza and Daly 1992) do not prescribe focusing on biodiversity or other compositional dynamics. Empirical evidence of the ecological consequences of biodiversity loss has led to a greater understanding of the interconnections among biodiversity (especially the importance of functionally critical species), ecosystem processes, and underlying mechanisms (Brussaard 1997; Loreau et al. 2001; Tilman et al. 2014; Thompson et al. 2015). Leopold repeatedly highlighted the importance of diversity for ecological functioning, especially of native species, native forms, and complex underlying mechanisms (Callicott 1993). While economic solutions involving market creation for certain ecosystem services (such as carbon sequestration) have seen success, similar efforts to protect biodiversity (through providing economic incentives) face many difficulties such as high transaction costs and incomplete property rights (Teytelboym 2019). Leopold's ideas provide a constructive focus on biodiversity (and other compositional characteristics) as an important dynamic in management of natural capital. As Berkes et al. (2012, p. 285) note, "The connections that Leopold saw between ecosystems and biodiversity on the one hand and human social and political processes on the other... are increasingly becoming the foundation of a contemporary science of sustainability" (Berkes et al. 2012).

Third, the guiding principles could prescribe sustainable use of natural capital in various socio-ecological practice contexts. Lant, Ruhl, and Craft (2008) describe a "tragedy of ecosystem services," which results from certain important natural capital rarely being traded in markets and overconsumption of commodified components of natural capital (such as fish or timber). As a result, many ecosystem services such as soil formation, and water purification could be underprovided or depleted. Trying to create market solutions for sustainable management of natural capital that provide non-market services depend on the evolution of common law of property and reform of economic incentives (Lant et al. 2008). The ecological economic arguments for management of natural capital largely focus on assigning monetary values to the different services provided by natural capital that contributes to human wellbeing (Costanza and Daly 1992). In addition to limits to the extent to which monetary values 
can be assigned for services provided by natural capital, such approaches also do not holistically represent human-nature relationships (Norgaard 2010). The proposed principles recognize the interdependencies between humans and nature, compared to monetary value attributions. Therefore, this article presents an alternative approach to monetary valuation-based ecological economic approaches for management of natural capital. ${ }^{2}$

\section{A common concept of land}

Several definitions of an ecosystem could be highlighted from pertinent literature. Coining the term in 1935 Tansley (1935) noted, in "an ecosystem the organisms and the inorganic factors alike are components" (p. 306) as "there could be no systems without them, and there is constant interchange of the most various kinds...not only between the organisms but between the organic and the inorganic" (p. 299). In his history of the concept of sustainability, Caradonna (2014, p. 91) defines an ecosystem as "a community of living organisms and nonliving entities that interact in myriad ways and through which nutrients cycle and energy flows." An ecosystem could be identified as an assemblage of plants and animals (including microorganisms) plus the abiotic environment interacting as a functional unit (Brussard et al. 1998; Alcamo et al. 2003). The dynamics of energy flow and nutrient cycles could be recognized as the organizational theory for ecosystems (Reiners 1986). However, nutrient cycles and energy flows are inadequate to answer questions such as "the biological basis for regulation and homeostasis, or how ecosystems respond to disturbances... Biologically driven dynamic processes are ultimately based on population and community properties" (Reiners 1986, p. 70). Reiners (1986) argues that in addition to energy flows and nutrient cycles, a third complementary approach built on interactions and connectedness properties must be recognized.

A biotic community could be outlined as a complex integrated assemblage constituting of interrelated and interdependent plants and animals with integrated responses, reactions, and co-actions that is a product of its environment (Phillips 1931; Taylor 1935; McGill et al. 2006). The interdependencies between the plants and the animals are as important as the interdependencies between the biotic and the abiotic environment (Taylor 1935). The biotic community possesses a special identity-it is indeed a mass-entity with a destiny peculiar to itself (Phillips 1931, p. 20). In

\footnotetext{
2 The ontological disagreement between philosophers and economists on the moral consideration of intrinsic value of the environment is considered beyond the scope of this article.
}

The Land Ethic essay, Leopold (1949, p. 204) "enlarges the boundaries of the community to include soils, waters, plants, and animals, or collectively: the land." According to Warren (2016, p. 180) "By the 1930s Leopold had begun referring regularly to land ${ }^{3}$ as a biotic community."

The compositional characteristics/identity is an important consideration in biotic communities (Phillips 1931), while that might not be an important consideration in ecosystems. Consideration of non-economic components and compositional dynamics are important from an ecological economics perspective as the non-economic parts could contribute to human wellbeing. Leopold (1949, p. 214) clearly included economic and non-economic components in the biotic community, where he noted,

"A system of conservation based solely on economic self-interest is hopelessly lopsided. It tends to ignore, and thus eventually to eliminate, many elements in the land community that lack commercial value, but that are (as far as we know) essential to its healthy functioning. It assumes, falsely, I think, that the economic -parts of the biotic clock will function without the uneconomic parts."

Leopold highlighted the importance and contribution of non-economic parts and compositional dynamics to the functioning of the whole community, by describing how "Some species of trees have been 'read out of the party' by economics-minded foresters because they grow too slowly, or have too low a sale value to pay as timber crops" (Leopold 1949, p. 212). Comparatively "In Europe ... the noncommercial tree species are recognized as members of the native forest community, to be preserved as such, within reason. Moreover some (like beech) have been found to have a valuable function in building up soil fertility" (Leopold 1949, p. 212).

Ecosystems and biotic communities could be considered paradigms in ecology that when taken together help to compose a more holistic view of ecologic functioning (Lindeman 1942). Similarly, Reiners (1986) argues that unless considered complementarily, the scientific understanding of ecosystems and biotic communities might not be complete (Reiners 1986).

It is clear that humans are a part of ecosystems and biotic communities. However, Leopold (1949, p. 215) clearly outlined human dependency on the biotic and abiotic components of the biotic community using food chains: "The lines of dependency for food and other services are called food chains. Thus, soil-oak-deer-Indian is a chain that has now been largely converted to soil-corn-cow-farmer." Roelofs (2011) notes that perceiving ecological systems

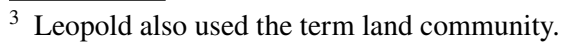


as "communities" would imbue moral significance for the care of the community. As Leopold (1949, p. 221) notes, "A land ethic, then, reflects the existence of an ecological conscience, and this in turn reflects a conviction of individual responsibility for the health of the land." By using the notion community and by clearly establishing humans as a dependent member of the community, Leopold's concept of biotic community clearly implies human obligation for care and health of the biotic community.

It is important to exemplify the connection between ecosystems and natural capital. The term "capital" has generally been used to describe the inputs necessary for the economic production processes such as machinery and money (Harte 1995; Ang and Van Passel 2012). The central concept of capital is the idea of a stock with the capacity to provide a flow of goods and/or services (Ekins et al 2003). Neo-classical economists mainly identified three types of capital: land, labor, and human-made capital (Ekins et al 2003). "Capital consists of durable produced goods that are used to make other goods...include structures like factories and houses, equipment like computers and machine tools, and inventories of finished goods and goods in process" (Samuelson and Nordhaus 2009, p. 658). In addition to economic identifications, Uzawa (2005) presents the concept of social common capital (comprising of natural capital, social infrastructure, and institutional capital) representing those services and institutional arrangements that are crucial to maintain human and cultural life at the community level. Recent pertinent literature outline several forms of capital: human-made or manufactured capital (e.g., machines, buildings), social capital (e.g., political institutions, social relationships), human capital (e.g., skills, education, knowledge), cultivated natural capital (e.g., forest plantations, wineries, farmland), and natural capital (e.g., fish, timber, and water) (Costanza and Daly 1992; Brand 2009; Ang and Van Passel 2012; Guerry et al. 2015). This article considers cultivated natural capital as a part of natural capital as they are guided by the same principles discussed later in Sect. 6. Human-made capital, social capital, and human skills, etc., are presumed to constitute human capital.

One of the most widely cited definitions of natural capital is by Costanza and Daly (1992, p. 38): "stock that yields a flow of valuable goods or services into the future." Costanza and Daly (1992) describe two different types of natural capital: renewable or active natural capital (RNC), and nonrenewable or inactive natural capital (NNC). The major defining characteristic of RNC is its substantial regenerative capacity (Costanza and Daly 1992). Frequent examples of RNC include population of fish (stock in this case) in the ocean that generates a flow of caught fish that go to the market, and trees (stock in this case) that generates a flow of cut lumber (Ekins 2003;
Spash and Clayton 1997). Comparatively, NNC is more passive and has a regenerative capacity of zero or close to zero (Costanza and Daly 1992; Harte 1995). Fossil fuels (such as coal) and mineral deposits are the most commonly cited examples.

In the context of ecosystems, the human-nature relationships are exemplified in ecosystem services. "Ecosystem services are the conditions and processes of ecosystems that generate-or help generate-benefits for people," which "result from the interactions among plants, animals, and microbes in the ecosystem, as well as biotic, abiotic, and human-engineered components of social-ecological systems" (Guerry et al. 2015, p. 7349). Ecosystem services were characterized by The Millennium Ecosystem Assessment (2006) under the primary categories of provisioning, regulating, cultural, and supporting services. While some services such as food and lumber represent provisioning services, others such as soil fertility, disease resistance, and recreational benefits represent supporting, regulating, and cultural services, respectively (Guerry et al. 2015). Recent literature exemplifies the connection between natural capital, ecosystems, and ecosystem services more clearly. Natural capital is the biotic and the abiotic components of ecosystems that yield ecosystem services (Ekins et al. 2003; Turner and Daly 2008).

Consideration of trees and fertile soils as natural capital presents an important implication as Leopold recognized the same as components of biotic communities. Leopold (1991b, p. 311) also highlighted the need to consider natural resources as integral parts within the biotic community by asserting that, "Land to the average citizen, is still something to be tamed, rather than something to be understood, loved, and lived with. Resources are still regarded as separate entities, indeed, as commodities, rather than as our cohabitants in the land community."

Synthesizing the above literature yields three important points pertaining to a common concept of land. First, from a natural capital (component/stock) perspective, both ecosystems and biotic communities are composed of biotic (animals and plants) and abiotic components (soil and water etc.) and the relationships between them. Therefore, the components considered as natural capital could be similar in both the ecosystem and biotic community paradigms. Second, the functional (energy flows and nutrient cycles) dynamics of ecosystem ecology and the community (compositional and structural) dynamics of biotic communities are both important to develop a holistic conception of ecosystem services provided by natural capital. Third, from an ethical (or obligatory) perspective, the biotic community concept exemplifies moral obligation (by humans) for the care of the community. 


\section{Weaknesses of the Costanza and Daly (1992) conceptualization of natural capital}

Several authors have pointed out the weaknesses of the stock-flow framework and the two categories of NNC and RNC as having an anthropocentric utilitarian lens and lacking in ability to adequately capture the functions, properties, and all of the contributions of natural capital to human wellbeing (Harte 1995; Spash and Clayton 1997; Ang and Van Passel 2012). The conceptualization of natural capital in Costanza and Daly (1992) as constituting of NNC and RNC presents two main weaknesses.

\subsection{NNC does not fit the stock-flow framework}

NNC (such as oil and coal) could be viewed as a long-term inventory "that will sit quietly until extracted and used, but once it is used it is gone" (Costanza and Daly 1992, p. 38). It is the depletion and liquidation of the inventory of stock of NNC that contributes to human wellbeing, rather than a flow that can be sustained over time (Costanza and Daly 1992). The connection between stocks and flows is indeed crucial from the capital perspective (Costanza and Daly 1992) and consideration of NNC as a type of natural capital might imply the concept of a natural capital stock yielding ecosystem services to be inaccurate. When extracted and processed, NNC follows the same demand and supply dynamics as any other human produced commodity.

\subsection{RNC and NNC are inadequate to exemplify the numerous workings of natural capital}

Recent literature defines natural capital more broadly compared to Costanza and Daly (1992). Guerry et al. (2015, p. 7348) defines natural capital as "the living and nonliving components of ecosystems-other than people and what they manufacture- that contribute to the generation of goods and services of value for people." Brand (2009, p. 608) describes natural capital as a "multidimensional meta-concept for a plurality of interrelated and heterogeneous stocks that perform various functions and services for human society."

While not defined as a specific type of natural capital, some components of natural capital are termed critical natural capital (CNC) based on their contribution to human wellbeing (Ang and Van Passel 2012). Douguet and O'Connor (2003, p. 237) define CNC "as any set of environmental resources which, at a prescribed geographical scale performs important environmental functions and for which no substitute in terms of manufactured, human or other natural capital currently exist." Examples of CNC include freshwater resources, climate regulation, and fertile soils (Brand 2009). While CNC is critical for sustaining human wellbeing, $\mathrm{CNC}$ is not defined as a type or a subset of natural capital, and the only logical explication of $\mathrm{CNC}$ is that certain environmental resources cannot be substituted.

Neither NNC nor RNC exemplify natural capital recognized as CNC such as freshwater or fertile soils. Ecologists conceive nature as a hierarchy of scales (Grumbine 1998). This hierarchical characteristic can be observed in natural capital as well. For example, while a tree provides lumber, a biologically diverse stand of trees (especially consisting of native species) could provide resistance to diseases. As Leopold (1991a, p. 269) notes, "interdependence between the complex structure of land and its smooth functioning... is one of its basic attributes." Natural capital as constituting of RNC and NNC does not reflect the hierarchical complexity and functioning of natural capital.

Pertinent literature recognizes the broader contribution of natural capital to human wellbeing by outlining that natural capital refers to both the various ways that the environment powers the economic subsystem and supports most aspects of human existence (Ekins 2003). The two categories of $\mathrm{NNC}$ and RNC are inadequate to capture the different ways natural capital contributes to human wellbeing and the hierarchical complexity of natural capital. Lin and Fyles (2015, p. 213) observe, "Leopold's land ethic, which is essentially a reimagining of the role of human beings in the land, was grounded in his ecological understanding of how the land works." Therefore, it could be possible to conceptualize a more dynamic and ecologically consistent view of natural capital based on the ideas of Leopold.

\section{Sustainable use in the context of natural capital and the land ethic}

One of the debates in ecological economics pertaining to management of natural capital address whether natural capital may be substituted by human-made capital. There are two positions in this debate: weak and strong sustainability (Figge 2005). The aim of this section is to summarize the main posits of the strong and weak sustainability discourse.

Noel and O' connor (1998, pp. 76-78) contend that weak sustainability (WS) "assumes that welfare is not dependent on a specific form of capital and that sustainability can be maintained by substituting human-made (manufactured) capital or human capital for natural capital," which means that depletion of one form of capital can be compensated by a surplus of the other. Critics of WS point out that the assumption that human capital could substitute natural capital is erroneous as different forms of capital have a complementary relationship (Costanza and Daly 1992). For example, fish stocks (natural capital) and fishing boats 
(human-made capital) are not substitutes but compliments (Costanza and Daly 1992; Figge 2005). Costanza and Daly (1992, p. 41) asserts that "if human-made capital were a perfect substitute for natural capital, then natural capital would also be a perfect substitute for human-made capital," which means there would be "no reason to develop and accumulate human-made capital in the first place!".

Many other examples can be described to demonstrate that the relationship between natural and human capital is overwhelmingly one of complementarity, not substitutability, which is the position of this article. WS-based thinking does not take into consideration how natural capital performs several environmental functions, in addition to providing inputs to the production system (Daly 1995). Human/manufactured capital lacks this multiple functionality. Therefore, it can be concluded that depletion of natural capital or substitution of natural capital does not represent sustainable use of natural capital. Consequently, it can be argued that WS does not provide a basis for sustainable use of natural capital.

The strong sustainability (SS) paradigm originates as a countermovement to WS paradigm: manufactured or human capital cannot be substituted for natural capital (Ang and Van Passel 2012). However, SS acknowledges that, resource substitution is viable if the two resources have similar characteristics and perform same function, such as aluminum for copper or aluminum for lumber (Costanza and Daly 1992; Figge 2005).

"Strong sustainability criterion" for policy specifies, "as a necessary condition for environmental sustainability, the maintenance of natural capital stocks at or above some threshold levels" (Noel and O'connor 1998, p. 76). Similarly, Goodland (1995, p. 10) defines environmental sustainability as "the maintenance of natural capital." From an intergenerational perspective, it can be assumed that "equity is achieved when each following generation has at least as much capital at its disposal as the preceding generation" (Solow 1974, p. 9). However, Spash and Clayton (1997, p. 143) note, "concern for environmental degradation has led to the suggestion that natural capital maintenance is a necessary but insufficient condition for a sustainable society." Mere presence of stock does not represent the capacity to generate ecosystem services. For example, a stand of trees or a stock of soil might not have a capacity for disease resistance or crop production, respectively. However, a stand of trees that is diverse and consisting of native species might have disease resistance capacity. Similarly, fertile soil would be able to produce crops. Therefore, sustainable use of natural capital requires a much more broader focus than specified by the strong sustainability criterion.

As outlined in Sect. 2, recognizing natural capital as biotic and abiotic components of biotic communities imply that the health of natural capital would depend on the health of the biotic community. For example, the health of the fish (RNC) in a lake depends on the quality of water in the lake and the availability of native plants that the fish feed on, among other factors. Therefore, the health of the fish in a lake depends on the overall health of the lake. As Leopold (1991b, p. 310) points out, "health is more than a sufficiency" of the presence of components, but it is a "state of vigorous self-renewal in each of them, and in all collectively." Ensuring healthy natural capital would require clearly identifying the characteristics of a healthy biotic community.

Leopold highlighted three criteria that could help exemplify the health of a biotic community that could present important implications for health of natural capital: stability, integrity, and beauty (Leopold 1949). Warren (2016) argues, by "stability" Leopold meant the ability of the land to maintain certain circulatory systems such as the ability to cycle nutrients efficiently and maintain its food chains over long periods of time. According to Warren (2016, p. 340), "Integrity" meant two overlying connotations for Leopold: "it meant the species needed to keep land stable, and it meant the full range of self-organized native plants and animals that had inhabited a place before industrial civilization arrived." Therefore, integrity represents the presence of crucial structural components of a biotic community and the efficient collective complex functioning of the interdependent parts of the whole community (Warren 2016). Warren (2016, p. 343) continues to claim "Beauty was not a mere subjective choice of the viewer ... It was a characteristic that arose when the parts of nature were linked harmoniously into a whole promoting the land's stability and long-term flourishing." Beauty indicates the harmonious productivity of a biotic community that is stable and retained integrity (Warren 2016).

Leopold's summary moral maxim (1949, p. 225) "a thing is right when it tends to preserve the integrity, stability and beauty of the biotic community. It is wrong when it tends otherwise" helps to outline several sustainable practices to preserve the health of a biotic community such as preserving soil health, preventing the extinction of species, performing appropriate restorations, ensuring survival of native species, and making any changes carefully (Warren 2016). As a result, sustainable use of natural capital should not only focus on maintenance of stock but also on ensuring the health of such stock within the context of the health of the biotic community.

\section{Reconceptualising natural capital based on the land ethic}

It must be noted that the types of natural capital described in this section are largely applicable in the context of a biotic community. As the scale increases, such as from local to 


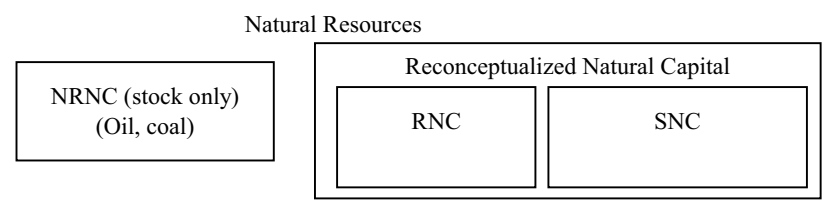

Fig. 1 Reconceptualized natural capital

global, the complexity and magnitude of environmental systems and processes make it challenging to describe global environmental systems as a specific type of capital. To this end, Callicott (2013, p. 97) contends that in light of recent developments in ecology, the ideas of "the land" need to be refined to represent the "norms of scale to the land ethic for both climatic and ecological dynamics."

Addressing the weaknesses of natural capital conceptualization outlined in Sect. 3 requires a reconfiguration of natural capital. This would require three refinements to the conception of natural capital. First, while NNC is considered a natural resource, it should not be considered as a type of natural capital. Reflecting this, natural resources such as oil, coal, and natural gas are re-named Nonrenewable Natural Commodities (NRNC). It is important to note that the discounting of NRNC as not a type of natural capital is consistent with other literature such as Hanson et al. (2012, p. 6) who contend,

"Minerals and fossil fuels-coal, oil, and natural gas-are examples of natural resources that are not ecosystem services. The quantity and quality of minerals and fossil fuels are not dependent upon the living component of existing ecosystems and therefore are not benefits derived from ecosystems."

Second, the description of Renewable Natural Capital (RNC) remains unchanged and will continue to represent stock that yields a flow of ecosystem services (largely considered provisioning services). Third, a new category of natural capital named Structural Natural Capital (SNC) is introduced. Consequently, RNC and SNC would comprise natural capital. Figure 1 depicts the reconceptualized natural capital.

It is important to clearly outline the differences between RNC and SNC. RNC has a capacity for regeneration where the stock would produce certain services of similar form. For example, a stock of fish would produce more fish, a stock of trees would produce timber, and a stock of seeds would produce new plants etc. Comparatively, SNC has the capacity to provide certain services (largely considered supporting and regulating services) through collective healthy functioning of biotic and abiotic components of biotic communities. Collective functioning represents both natural processes (such as nutrient cycling and energy flows) and compositional dynamics (such as biodiversity and presence of key/important species). Costanza and Daly (1992) ${ }^{4}$ noted that RNC also performs certain waste assimilative services (such as trees absorbing $\mathrm{CO}_{2}$ from the atmosphere, aquatic plants absorbing pollutants and excessive nutrients from water). This article recognizes waste assimilative services as provided by SNC.

Several examples of SNC stock can be outlined: a biologically diverse assemblage of species/native trees (SNC stock) that could yield disease resistance (SNC flow); a mycorrhizal network consisting of tree roots and mycorrhizal fungi (SNC stock) that can mobilize water and nutrients (SNC flow); soil organisms (SNC stock) that breakdown decaying organic matter that contributes to soil fertility (SNC flow); a colony of Bees (SNC stock) that provide pollination services (SNC flow); and tree canopy/stories (SNC stock) in a forest that can regulate climate (SNC flow). SNC stock represents not only the presence of certain biotic and abiotic components (such as soil organisms, microorganisms, and organic matter in the context of soil) but also a healthy state of those components (soil heavily treated with pesticides or soil that is very dry or exposed to high temperatures can kill soil organisms), with functioning natural processes of nutrient cycling, energy flows, and/or compositional characteristics. SNC fits the stock-flow framework in that it represents a certain type of natural capital stock (or a particular configuration) that has the capacity to produce a flow of ecosystem services.

It is important to note component overlap between RNC and SNC in certain contexts that demonstrates the multifunctional nature of natural capital. For example, a tree produces timber, which is considered as RNC. Simultaneously, the same tree could be considered as SNC, as the same tree is a part of nutrient cycling and energy flow processes that yield supporting services (such as soil fertility or production of Oxygen) and regulating services (such as climate regulation or water purification). If the tree is of a specific type (such as a native species or has certain disease resistant qualities), then the tree is also part of compositional attributes that yield regulating services (such as disease resistance). Bees represent similar overlap. Bees produce honey, which is considered an RNC. Bees are also considered SNC for the pollination services they provide, which is a regulating service. Comparatively soil microorganisms would only be a SNC component. McIntyre et al. (2007) found that fish species vary widely in the rates at which they excrete nitrogen and phosphorus. Therefore, certain fish species would be important as SNC (as a component of nutrient cycling processes) in addition to being an RNC as fish for human consumption.

\footnotetext{
4 Termed a sink function in Costanza and Daly (1992). Costanza and Daly (1992) outline two functions of RNC: source and sink functions.
} 
Categorizing natural capital into RNC and SNC facilitate the definition of natural capital in the context of a biotic community as the healthy and active biotic and abiotic components that yields ecosystem services, which contribute to human wellbeing. The terms "healthy" and "active" are crucial to understand the difference between the natural capital definition proposed above and definitions based simply on stocks and flows. Influenced by Leopold's thinking, health could be outlined as the capacity of natural capital for selfrenewal. For example, fish would be able to reproduce and soil organisms would be able to cycle nutrients to maintain soil fertility. Active implies the presence of open circulatory processes between components (such as soil organisms breaking down organic matter or process of nutrient metabolization). The health and activeness of natural capital depends on and needs to be perceived within the health of the biotic community. For example, a lake (biotic community) that is polluted with chemicals or with harmful algal blooms does not represent healthy conditions or presence of active circulatory processes conducive for fish (RNC) production for human consumption.

RNC and SNC exemplifies interdependency between humans and the biotic community. The interdependency highlights the moral responsibility of humans as members of the biotic community to care for the health of natural capital (by focusing on the health of biotic community), and the ability of SNC and RNC to contribute to human wellbeing. If humans care for SNC and RNC, then natural capital will generate services that contribute to human wellbeing. For example, fertile soil is crucial for crop production. However, soil fertility depends on humans adopting certain ecologically wise practices or not adopting certain damaging practices. Leopold (1949, p. 217) elucidates this interdependence by stating, "Fertility is the ability of soil to receive, store, and release energy. Agriculture, by overdrafts on the soil, or by too radical a substitution of domestic for native species in the superstructure, may derange the channels of flow or deplete storage." "Decline in soil fertility reduces not only the gross yields of crops, but the nutritional value of the crops, and the welfare of animals which eat them" (Leopold 1991b, p.314). Specific principles to guide sustainable use of NRNC, RNC, and SNC are described in the next section.

\section{Guiding principles for sustainable use of natural capital}

Assimilating Leopold's ideas, a set of guiding principles can be proposed for sustainable use of Nonrenewable Natural Commodities (NRNC), Renewable Natural Capital (RNC), and Structural Natural Capital (SNC). The principles are not independent, but build off each other. The principles described in this section are best applicable in the context of a biotic community.

\subsection{Understanding the dynamics of natural capital}

As described by Warren (2016, p. 15), a flawed and fragmented view of nature prompted Leopold to declare the need for an "ecological conscience" representing "a scientific understanding of land and the emergence of a new set of cultural values." RNC and SNC are intricately linked and the human knowledge of these synergistic workings are not complete. The recognition of interlinkages between RNC and SNC are important for two main reasons. First, the interlinkages highlight how SNC facilitates and supports the regenerative processes of RNC and the need to protect and nurture such synergistic interlinkages. As described by Daly (1995) there is a clear link between the environmental function (yielding ecosystem services), and the environmental structure (what is needed for operation of the environmental function). For example, fertile soils (generated through services provided by SNC) support production of crops from seeds (RNC). Secondly, the interlinkages highlight the importance of activating measures to sustain the health of biotic communities so that SNC can support the regeneration of RNC. For example, fish (RNC) require certain water quality properties (such as temperature, turbidity, and $\mathrm{pH}$ ) and presence of food sources to be healthy and produce new fish. If the quality of water (through services provided by $\mathrm{SNC}$ ) is negatively impacted (reflected through deterioration of the health of biotic community), then the fish will struggle to survive and the flow of new fish will be lost. As Leopold (1991a, p. 271) noted, "Whatever may be the equation for men and land, it is improbable that we as yet know all of its terms." Similarly, Alcamo et al. (2003, p. 1) claims, "Better information cannot guarantee improved decisions, but it is a prerequisite for sound decision-making." As a result, the first guiding principle prescribes gaining insights to understand the workings of natural capital.

Guiding principle 1: More information, research, and investments are needed to understand and nurture the workings of RNC and SNC.

Guiding principle 2 articulates the importance of traditional ecological knowledge and local knowledge to understand and recognize the symptoms and indicators of diminished regenerative capacity of RNC and when the health of SNC is threatened by human activities. For example, it may be possible to identify early-warning signals of a fish population under stress or a stand of trees under stress. The condition of the health of the biotic community might indicate such diminished capacity of natural capital. As sustainability is interwoven within a specific locational context, traditional ecological knowledge represents a "foundational 
holistic knowledge system" rich with "local expertise" useful for developing practical action (Schwann 2018, p. 179). Ostrom (2009, p. 420) also notes, understanding humannature systems "requires knowledge about specific variables and how their component parts are related" and local knowledge accumulated over time helps to understand contextual capacity dynamics and how they have changed over time.

Guiding principle 2: Traditional ecological knowledge and local knowledge are critical to recognize the symptoms and indicators of diminished regenerative capacity of RNC and when health of SNC is threatened by human activities.

\subsection{Production and consumption of NRNC}

Sustainable use principles 3-6 represent prescriptions for production and consumption of NRNC. NRNC such as oil and coal only benefit humans and the different ways these resources benefit humans can be mapped for substitution. For example, solar or wind instead of coal to generate electricity, or natural gas instead of coal to generate heat. Coztanza and Daly (1992, p. 44) prescribe rules for management of NNC, which are applicable to NRNC: "should be exploited, but at a rate equal to the creation of renewable substitutes." A specific type of NRNC can be substituted by another NRNC or ideally and prudently by an RNC.

Guiding principle 3: NRNC (such as coal and oil) benefit only humans and the different ways these resources benefit humans can be mapped for substitution according to the concept of weak sustainability.

NRNC such as oil, coal, and other materials such as helium play significant roles that contributes to human wellbeing. "Economic progress and human development are seen to be dependent on both ecological processes and the sufficiency of potentially scarce resources" (Harte 1995, p. 158). Since NRNC consists of only stocks, it is critical to utilize such stocks in ways that would maximize use efficiencies.

Guiding principle 4: Initiatives that would maximize resource use efficiencies such as recycling and material recovery would prolong the usable time period of the NRNC stock.

Two more guiding principles need to be specified that apply to production and consumption of NRNC. Importantly, it must be noted that if NRNC generate wastes through the extraction and consumption processes, then the usage rate of NRNC is limited by the waste assimilative capacity of SNC. This is the most critical sustainable use principle for consumption of NRNC. Not abiding by this principle can lead to significant negative impacts on human health and wellbeing. For example, current emission levels of $\mathrm{CO} 2$ from burning fossil fuels are greater than the assimilative capacities of carbon sinks such as forests, leading to $\mathrm{CO} 2$ accumulating in the atmosphere. Scientists widely agree that accumulating $\mathrm{CO} 2$ in the atmosphere can cause (and is causing) catastrophic climate change and other concomitant effects such as sea level rise (Guerry et al. 2015). Therefore, principle 5 outlines significant implications for human health and wellbeing.

Guiding principle 5: Consumption of waste generating NRNC should be limited to less than the waste assimilative capacity of SNC.

Human activities such as mountain top mining or oil development in the Arctic National Wildlife Refuge to extract NRNC can have significant negative impacts on the health of the respective biotic communities, which could have negative impacts on the RNC and SNC of such biotic communities. In addition to the polar bears and the caribou, the Inupiats that live in the North Slope region are heavily dependent on the RNC (such as fish and caribou) and SNC (rich biodiversity) of the Arctic National Wildlife Refuge (biotic community). Therefore, impacts of NRNC extraction should be perceived within a broader framework. Leopold claims (1949, p. 8) that "We abuse land because we regard it as a commodity belonging to us. When we see land as a community to which we belong, we may begin to use it with love and respect. There is no other way for land to survive the impact of mechanized man." These ideas collectively frame guiding principle 6 .

Guiding principle 6: Impacts of extraction and consumption of NRNC must be perceived within a broader ecological framework, considering the impacts on $\mathrm{RNC}, \mathrm{SNC}$, and the overall health of the biotic community.

\subsection{Production and consumption of RNC}

Rules prescribed by Costanza and Daly $(1992$, p. 44) for consumption of RNC continue to be applicable: "From a resource use standpoint, RNC should be exploited on a profit-maximizing sustained- yield basis." The flows of RNC such as lumber and fish demonstrate the resource regenerative capacity of the RNC. Harvesting rates of resources generated from a stock of RNC such as fish stocks (producing more fish) or trees (producing timber) should not exceed the regeneration rates of such stock (Costanza and Daly 1992) within a considered time period (such as yearly).

Guiding principle 7: Harvesting/usage rates of RNC should not exceed regeneration rates (Costanza and Daly 1992). 
Continued exploitation of RNC in excess of natural regeneration rates can deplete the stock thereby diminishing the regeneration levels. Some researchers argue that exploitation of renewable resources at rates exceeding the natural regeneration rate can turn such resources to nonrenewable resources (Costanza and Daly 1992). This article does not take this view. From Leopold's (1949, p. 221) perspective, "health is the capacity of the land for self-renewal" and "a particular resource may be healthy or sick" (Leopold, 1991b, p. 311). Therefore, when renewable resource stocks are depleted to such levels that it cannot regenerate, it represents an unhealthy (or sick) state.

Certain flow services of RNC (such as lumber and fish) can be substituted by other RNC or even in some cases by NRNC. For example, substitution of steel or aluminum in construction for lumber and substitution of fish with tofu. However, and more importantly, the possibility of substitution is limited to the specific flow service of RNC. For example, while steel can be substituted for lumber, it is not a valid argument for substitution of trees (or a stand of trees), as trees (as SNC) play vital roles in provision of other ecosystem services such as carbon sequestration, soil fertility, and providing habitat for animals etc. Since current technology is not viable or capable of producing such human-made substitutes, use of RNC must be guided by principles of strong sustainability.

Guiding principle 8: The substitution argument for RNC is valid if and only if all of the different ecosystem services that are provided by a certain $\mathrm{RNC}$, and the interlinkages between RNC and SNC can be substituted.

\subsection{Protection and care of SNC}

Some biotic or abiotic components of biotic communities might not directly generate any value (or service) to humans, but could represent critical components of SNC. For example, non-commercial fish species form critical parts of food chains of commercial fisheries and contribute to biodiversity of such fisheries. Therefore, care for SNC requires not only sustaining components of biotic communities that benefit humans but also the components that do not directly benefit humans, but are important for collective functioning. Leopold (1991a, p. 272) compares "biotic farming" to "agriculture" to exemplify such sustainable practices where,

"Biotic farming, in short, would include wild plants and animals with tame ones as expressions of fertility. To accomplish such a revolution in the landscape, there must of course be a corresponding revolution in the landholder. The farmer who now seeks merely to preserve the soil must take account of the superstructure as well: a good farm must be one where the wild fauna and flora has lost acreage without losing its existence" (Leopold 1991a, p. 272).

Therefore, it is important to sustain biotic and abiotic components of biotic communities that do not directly benefit humans considering the significance of such components to functioning of SNC.

Guiding principle 9: Care for SNC requires not only sustaining biotic and abiotic components of biotic communities that benefit humans (considered natural capital) but also the components that do not directly benefit humans, but are important for collective functioning.

Lack of viable substitutes for SNC require care for the biotic and abiotic components of biotic communities that constitute SNC, according to the concept of strong sustainability. For example, while the artificial trees developed by Klaus Lackner can remove $\mathrm{CO} 2$ from the atmosphere, they cannot play any role in nutrient cycling or biodiversity. Presence of a few crucial biotic or abiotic components that activate circulatory systems within the biotic community, such as the presence of microorganisms in soil, presence of native species, predator-prey relationships, and pollinatorpollinated relationships are crucial for healthy SNC. When crucial components are lost, SNC would lose the capacity to provide ecosystem services. The aim of sustainable practices should be to sustain biotic communities such that no crucial components required for healthy and active functioning of SNC are lost. Leopold (1991b, p. 315) notes that "the land should retain as much of its original membership as is compatible with human land-use. The land must of course be modified, but it should be modified as gently and as little as possible."

Guiding principle 10: Lack of viable substitutes for SNC require care for biotic communities such that all the crucial biotic and abiotic components that constitute SNC are sustained.

\section{Conclusion}

Inspired by Leopold's land ethic, this article reconceptualizes natural capital. In my view, the reconceptualized natural capital is ecologically consistent and captures the numerous contributions of natural capital to human wellbeing. The guiding principles presented in Sect. 6 could facilitate the development of sustainable practices to sustain biotic communities (and there by natural capital) in a healthy state, where humans recognize and respect the synergistic interlinkages with natural capital as a member of the biotic community. 
While the reconceptualized natural capital presented in this article tries to capture the essence of human-nature relationships and the workings of nature, the concept of natural capital cannot capture all of the complexities and the workings of nature. No single framework might be able to do that. However, the reconceptualized capital types and the guiding principles presented situate humans as a member of the biotic community and prescribe ways to sustain healthy biotic communities.

Funding No funding was received for this study.

Availability of data and material Not applicable.

Code availability Not applicable.

\section{Declaration}

Conflict of interest The author declares that there is no conflict of interest.

Open Access This article is licensed under a Creative Commons Attribution 4.0 International License, which permits use, sharing, adaptation, distribution and reproduction in any medium or format, as long as you give appropriate credit to the original author(s) and the source, provide a link to the Creative Commons licence, and indicate if changes were made. The images or other third party material in this article are included in the article's Creative Commons licence, unless indicated otherwise in a credit line to the material. If material is not included in the article's Creative Commons licence and your intended use is not permitted by statutory regulation or exceeds the permitted use, you will need to obtain permission directly from the copyright holder. To view a copy of this licence, visit http://creativecommons.org/licenses/by/4.0/.

\section{References}

Alcamo J, Ash NJ, and Butler CD, et al. (2003). Ecosystem and human well-being. A framework for assessment. Millennium Ecosystem Assessment. Washington, D.C: Island Press

Ang F, Van Passel S (2012) Beyond the environmentalist's paradox and the debate on weak versus strong sustainability. Bioscience $62: 251-259$

Aronson J, Milton SJ, Blignaut JN (eds) (2007) Restoring natural capital: the science, business, and practice. Island Press, Washington, D.C

Berkes F, Doubleday NC, Cumming GS (2012) Aldo Leopold's land health from a resilience point of view: self-renewal capacity of social-ecological systems. EcoHealth 9(3):278-287

Boehnert J (2015) The green economy: reconceptualizing the natural commons as natural capital. Environ Commun 10:1-23

Brand F (2009) Critical natural capital revisited: ecological resilience and sustainable development. Ecol Econ 68:605-612

Brussaard L (1997) Biodiversity and ecosystem functioning in soil. Ambio 26:563-570

Brussard PF, Reed JM, Tracy CR (1998) Ecosystem management: what is it really? Landsc Urban Plan 40:9-20

Callicott JB (1993) The land ethic today. Topoi 12:41-51

Callicott JB (2013) Thinking like a planet: the land ethic and the earth ethic. Oxford University Press, New York
Caradonna JL (2014) Sustainability: a history. Oxford University Press, New York

Costanza R, Daly HE (1992) Natural capital and sustainable development. Conserv Biol 6:37-46

Daly HE (1995) On Wilfrid Beckerman's critique of sustainable development. Environ Values 4:49-55

Dalziel P, Saunders C and Saunders J (2018) Local government and natural capital. In: Wellbeing economics. Cham: Palgrave Macmillan

De Groot R, Van der Perk J, Chiesura A, Van Vliet A (2003) Importance and threat as determining factors for criticality of natural capital. Ecol Econ 44:165-185

Douguet J-C, O'Connor M (2003) Maintaining the integrity of the french terroir: a study of critical natural capital in its cultural context. Ecol Econ 44:233-254

Ekins P (2003) identifying critical natural capital conclusions about critical natural capital. Ecol Econ 44:277-292

Ekins P, Simon S, Deutsch L, Folke C, De Groot R (2003) A Framework for the practical application of the concepts of critical natural capital and strong sustainability. Ecol Econ 44(2/3):165-185

Farley J (2008) The role of prices in conserving critical natural capital. Conserv Biol 22:1399-1408

Fenech A, Foster J, Hamilton K, Hansell R (2003) Natural capital in ecology and economics: an overview. Environ Monit Assess $86: 3-17$

Figge F (2005) Capital substitutability and weak sustainability revisited: the conditions for capital substitution in the presence of risk. Environ Values 14(2):185-201

Flader SL (1974) Thinking like a mountain: Aldo Leopold and the evolution of an ecological attitude toward deer, wolves and forests. University of Missouri Press, Columbia

Goodland R (1995) The concept of environmental sustainability. Annu Rev Ecol Syst 26:1-24

Grumbine RE (1998) Seeds of ecosystem management in Leopold's A Sand County Almanac. Wildl Soc Bull 26(4):757-760

Guerry AD, Polasky S, Lubchenco J, Chaplin-Kramer J et al (2015) Natural capital and ecosystem services informing decisions: from promise to practice. Proc Natl Acad Sci USA 112(24):7348-7355

Hanson C, Ranganathan J, Iceland C and Finisdore J (2012). The corporate ecosystem services review: guidelines for identifying business risks and opportunities arising from ecosystem change. Version 2.0. World Resources Institute

Harte MJ (1995) Ecology, sustainability, and environment as capital. Ecol Econ 15:157-164

Lant CL, Ruhl JB, Kraft SE (2008) The tragedy of ecosystem services. Bio Sci 58(10):969-974

Leopold A (1949) A sand county almanac, and sketches here and there. Oxford University Press, New York

Leopold A (1991) A biotic view of land. In: Flader SL, Callicott JB (eds) The river of the mother of god and other essays. University of Wisconsin Press, Madison, pp 266-273

Leopold A (1991) Conservation: in whole or in part. In: Flader SL, Callicott JB (eds) The river of the mother of god and other essays. University of Wisconsin Press, Madison, pp 310-319

Lin QF (2013) Aldo Leopold: reconciling ecology and economics. Mind Nat 6(1):23-34

Lin QF (2014) Aldo Leopold's unrealized proposals to rethink economics. Ecol Econ 108:104-114

Lin QF (2020) A Sand County Almanac at 70: the significance of Leopold's life-work for socio-ecological practice and research. Socio Ecol Pract Res 2:1-2

Lin QF, Fyles JW (2015) Following in Aldo Leopold's footsteps: humans-in-ecosystem and implications for ecosystem health. In: Brown PG, Timmerman P (eds) ecological economics for the anthropocene: an emerging paradigm. Columbia University Press, New York, pp 208-233 
Lindeman R (1942) The trophic-dynamic aspect of ecology. Ecology 23:399-418

Loreau M, Naeem S, Inchausti P, Bengtsson J et al (2001) Biodiversity and ecosystem functioning: current knowledge and future challenges. Science 294:804-808

McGill BJ, Enquist BJ, Weiher E, Westoby M (2006) Rebuilding community ecology from functional traits. Trends Ecol Evol 21:178-185

McIntyre PB, Jones LE, Flecker AS, Vanni MJ (2007) Fish extinctions alter nutrient recycling in tropical freshwaters. Proc Natl Acad Sci USA 104:4461-4466

Meine C (2020) From the land to socio-ecological systems: the continuing influence of Aldo Leopold. Socio Ecol Pract Res 2:31-38

Millennium Ecosystem Assessment. (2006). Ecosystems and human well-being: a framework for assessment. A report of the Conceptual Framework Working Group of the Millennium Ecosystem Assessment. Washington, DC: Island Press

Noël JF, O’Connor M (1998) Strong sustainability: towards indicators for sustainability of critical natural capital. In: Faucheux S, O'Connor M (eds) Valuation for sustainable development: methods and policy indicators. Edward Elgar, Cheltenham, pp 75-97

Norgaard RB (2010) Ecosystem services: from eye-opening metaphor to complexity binder. Ecol Econ 69:1219-1227

Ostrom E (2009) A general framework for analyzing sustainability of social-ecological systems. Science 325:419-422

Pelenc J, Ballet J (2015) Strong sustainability, critical natural capital and the capability approach. Ecol Econ 112:36-44

Phillips J (1931) The biotic community. J Ecol 19(1):1-24

Reiners WS (1986) Complementary models for ecosystems. Am Nat 127(1):59-73

Roelofs L (2011) There is no biotic community. Environ Philos 8(2):69-94

Samuelson P, Nordhaus W (2009) Economics. McGraw-Hill, New York

Schultz L, Folke C, Österblom H, Olsson P (2015) Adaptive governance, ecosystem management, and natural capital. Proc Natl Acad Sci USA 112:7369-7374

Schwann A (2018) Ecological wisdom: reclaiming the cultural landscape of the Okanagan Valley. J Urban Manag 7:172-180

Solow R (1974) The economics of resources or the resources of economics. Am Econ Rev 64:1-14

Spash CL, Clayton AM (1997) The maintenance of natural capital: motivations and methods. In: Light A, Smith JM (eds) Space, place and environmental ethics. Rowman \& Littlefield, Lanham, pp 143-173
Tansley AG (1935) The use and abuse of vegetational concepts and terms. Ecology 16:284-307

Taylor WP (1935) Significance of the biotic community in ecological studies. Quart Rev Biol 10:291-307

Teytelboym A (2019) Natural capital market design. Oxf Rev Econ Policy 35(1):138-161

Thompson RM, Brose U, Dunne JA, Hall RO et al (2012) Food webs: reconciling the structure and function of biodiversity. Trends Ecol Evol 27:689-697

Tilman D, Isbell F, Cowles JM (2014) Biodiversity and ecosystem functioning. Annu Rev Ecol Evol Syst 45:471-493

Turner RK, Daily GC (2008) The ecosystem services framework and natural capital conservation. Environ Resour Econ 39:25-35

Uzawa H (2005) Economic analysis of social common capital. Cambridge University Press, New York

Wackernagel M, Rees W (1997) Perceptual and structural barriers to investing in natural capital: economics from an ecological footprint perspective. Ecol Econ 20(1):3-24

Warren JL (2016) Aldo Leopold's Odyssey: rediscovering the author of the sand county almanac, 10th Anniversary. Island Press, Washington, DC

Xiang W-N (2019) Ecophronesis: the ecological practical wisdom for and from ecological practice. In: Yang B, Young RF (eds) Ecological wisdom: theory and practice. Springer, Singapore, pp 13-32

Young RF (2016) Modernity, postmodernity, and ecological wisdom: toward a new framework for landscape and urban planning. Landsc Urban Plan 155:91-99

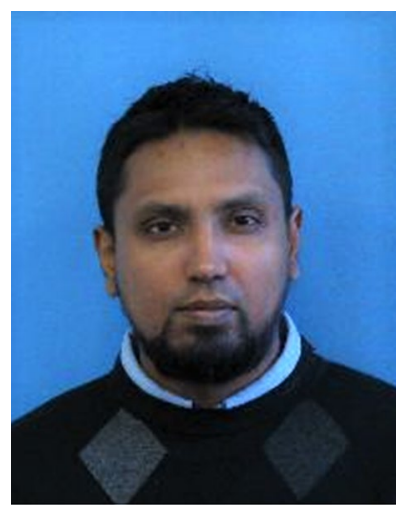

Felix N. Fernando is an Assistant Professor of Sustainability and the Coordinator of the Graduate Certificate in Sustainability at the Hanley Sustainability Institute at the University of Dayton. Felix teaches undergraduate and graduate courses in Sustainability and works with community partners to nurture and enhance sustainability initiatives in the greater Dayton area. 